\title{
The role of massage in the management of the athlete: a review
}

\author{
Michael J. Callaghan GradDipPhys, MCSP \\ Department of Physiotherapy, Royal Liverpool University Hospital, Liverpool, UK \\ Honorary Chartered Physiotherapist, British Cycling Federation
}

\begin{abstract}
Massage has been a therapeutic modality in all cultures since early civilization and has had a long tradition of use in the sporting context. However, there has been a paucity of scientific evidence of the physiological, psychological and therapeutic effects of commonly used massage techniques. This paper reviews the early and more recent studies on the effects of massage and also the more recent literature on its use on the sports person. Little agreement was found in English publications of the efficacy of massage and there were contradictory findings as to the optimum technique and length of time of application. It is clear that the role of massage - a time-consuming technique for a physiotherapist to perform - needs to be evaluated further in order to resolve some contentious issues arising about this mode of treatment and to justify its use.
\end{abstract}

Keywords: Massage, therapeutic effects, physiological effects, sportsperson, physiotherapy

Massage has been a therapeutic modality used by man since early civilization. Kamenet $z^{1}$ described the origin of the history of massage starting in the early civilizations of Babylon, Assyria, China, India, Ancient Greece and Rome. Massage continued to be used in the middle ages, the Renaissance, and through to the 20th century.

In the early 19th century, medicine and science made great progress in a desire for greater accuracy, understanding and the questioning of established doctrine. It was mainly in the last quarter of the 19th century that massage began to be studied and researched, while the 20th century saw the development of new techniques and systems. Kamenetz ${ }^{1}$ concluded that massage had declined over the greater part of the 20th century and proposed three reasons for this decline:

1. The development of the pharmaceutical industry

2. New machines supplanted older forms of physical therapy

3. Dehumanization in the relationship between therapist and patient.

Address for correspondence: Michael J. Callaghan, Department of Physiotherapy, Royal Liverpool University Hospital, Prescot Street, Liverpool L7 8XP, UK

(C) 1993 Butterworth-Heinemann Ltd 0306-3674/93/010028-06
Scull $^{2}$ advocated the use of massage as an 'indispensable agency' in the control of significant features of diverse syndromes such as poliomyelitis, anaemia, arthritis, cardiac oedema and nervous conditions. The physiological basis for these techniques was speculative.

It was also noted that the nucleus of physical therapy of rest, massage, heat and exercise had not changed over many years except for the use of X-rays and radium and that massage should be administered by a person of technical skill with anatomical, physiological and pathological knowledge.

Whereas the use of massage advocated by Scull ${ }^{2}$ has all but disappeared from use in hospital physiotherapy departments, the use of massage for the sports person has maintained a high profile and is an integral part of an athlete's conditioning ${ }^{3}$ even though its role may have been partially overvalued ${ }^{4}$.

From a scientific viewpoint, however, the use of massage in the sporting context has become contentious and flaws have been found in the claims by workers in the early part of the 20th century.

\section{Massage techniques}

Although massage technique may vary considerably between therapists, classical massage consists of a number of basic techniques which have remained essentially unchanged for centuries ${ }^{4,5}$. These techniques are referred to as Swedish massage $e^{6,7}$ and are comfortable, palliative and favoured by chartered physiotherapists.

There are also diverse forms of massage such as connective tissue massage $e^{4,8,9}$; underwater massage $^{4}$; shiatsu and acupressure ${ }^{5}$.

The five basic techniques of classical massage are effleurage, pétrissage, friction, tapôtement and vibration.

Effleurage (or stroking) is a deep stroking that should be in the direction of venous or lymph flow. Superficial effleurage should be centripetal. The palm of the hand is used and should conform to the contour of the body being treated. It was hinted ${ }^{2}$ that every massage session should begin and end with effleurage simply because it was the most gentle technique and it served as an introductory procedure to the other techniques. 
Pétrissage (or kneading) is a deeper technique than effleurage and is directed towards the muscles. The fingers and closed thumbs work like tongs grasping the tissues gently. The direction being distal to proximal centripetally. A distinction has been made between pétrissage and kneading in that more tissue is lifted, squeezed and moved in kneading ${ }^{5}$.

Friction (or rubbing) should be done in a slow elliptical or circular movement with the thenar eminence or, more specifically, the finger tips. Frictions should begin with light pressure and become progressively deeper. 'Gelotripsy' has been described as a violent removal of muscle hardening, a technique which could cause bleeding within a muscle due to deep, strong pressure ${ }^{4}$. The use in this context is therefore controversial.

Deep friction massage should not be confused with deep transverse frictions which have been described as having a fourfold effect:

1. Traumatic (local) hyperaemia

2. Movement of the deep tissues and prevention of adhesion formation

3. Increased tissue perfusion

4. Mechanoreceptor stimulation ${ }^{10}$.
Local hyperaemia was said to have a lasting enhancement of the blood supply and hence analgesia by increasing the speed of destruction of Lewis's P substance which is a factor responsible for pain. It was not explained how or if this differed from increased tissue perfusion.

Tapôtement (or hacking) is a series of gentle blows with the ulnar border of each hand. Other than causing hyperaemia in the skin, the primary effect is acoustic and could be detrimental if not used with extreme caution and restraint ${ }^{4}$. There have been vague guidelines stated by some authors cautioning against over-vigorous application of some techniques $^{4,10}$ and equally vague comments by others ${ }^{10}$ that gentle massage was neither useful nor harmful.

Vibration (or shaking) is used on the extremities and is said to lower muscle tone ${ }^{4}$. The therapist can elevate the extremity to encourage the venous and lymphatic return and then shake the limb.

In addition to the techniques listed, there have been many other variations with differences in masseur expertise and time of application. This lack of standardization renders comparison of studies difficult (Table 1).

Table 1. Summary of massage regimens described in literature

\begin{tabular}{|c|c|c|c|c|}
\hline Author & Masseur & Technique & Area & Time \\
\hline Balke et al. ${ }^{24}$ & Not specified & $\begin{array}{l}\text { Vibratory mechanical } \\
\text { massage } \\
\text { Manual massage not } \\
\text { specified }\end{array}$ & $\begin{array}{l}\text { Upper and lower leg } \\
\text { muscles }\end{array}$ & 3 min each group \\
\hline Hovind and Nielsen ${ }^{15}$ & Physical therapist & $\begin{array}{c}\text { Pétrissage and } \\
\text { tapôtement }\end{array}$ & $\begin{array}{l}\text { Vastus lateralis } \\
\text { Brachioradialis }\end{array}$ & 2 min each group \\
\hline Arkko et al. ${ }^{17}$ & Experienced therapist & $\begin{array}{l}\text { Shaking } \\
\text { Kneading } \\
\text { Frictions } \\
\text { Stroking }\end{array}$ & Whole body massage & $60 \mathrm{~min}$ \\
\hline Hansen and Kristensen ${ }^{16}$ & $\begin{array}{l}\text { Qualified physical } \\
\text { therapist }\end{array}$ & Effleurage & Calves & $5 \mathrm{~min}$ \\
\hline Wakim et al. ${ }^{11}$ & Physician & $\begin{array}{l}\text { Deep stroking } \\
\text { Kneading } \\
\text { Frictions } \\
\text { Modified Hoffa technique }\end{array}$ & Whole lower limb & $15-20 \mathrm{~min}$ each limb \\
\hline Ernst et al. ${ }^{19}$ & Not specified & Standard manual massage & Whole body & $20 \mathrm{~min}$ \\
\hline Sullivan et al. ${ }^{21}$ & $\begin{array}{l}\text { Person experienced in } \\
\text { massage }\end{array}$ & $\begin{array}{l}\text { Pétrissage one-handed } \\
0.5 \mathrm{~Hz} \text { rhythm }\end{array}$ & Calves and hamstrings & 4 min each group \\
\hline Boone et al. ${ }^{26}$ & Sports massage therapist & $\begin{array}{l}\text { Alternating deep strokes } \\
\text { broad cross fibre } \\
\text { strokes }\end{array}$ & Lower extremities & $30 \mathrm{~min}$ \\
\hline Drews et al. ${ }^{28,29}$ & Not specified & Not specified & Not specified & $30 \mathrm{~min}$ \\
\hline Wiktorrson et al. ${ }^{27}$ & Professional masseur & Kneading & All major leg muscles & $6-15 \mathrm{~min}$ \\
\hline Carafelli et al. ${ }^{25}$ & Not specified & $\begin{array}{l}\text { Vibratory mechanical } \\
\text { massage }\end{array}$ & Quadriceps group & $4 \mathrm{~min}$ \\
\hline Morelli et al. ${ }^{20}$ & Not specified & $\begin{array}{c}\text { Pétrissage one-handed } 30 \\
\text { manipulations per min }\end{array}$ & Calf muscle & $3 \mathrm{~min}$ \\
\hline Ebel and Wisham ${ }^{12}$ & Not specified & $\begin{array}{l}\text { Kneading } \\
\text { Deep stroking }\end{array}$ & Calf muscle & $10 \mathrm{~min}$ \\
\hline Harmer $^{7}$ & $\begin{array}{l}\text { Licenced massage } \\
\text { technician }\end{array}$ & $\begin{array}{l}\text { Effleurage } \\
\text { Pétrissage }\end{array}$ & Total body & $30 \mathrm{~min}$ (approximately) \\
\hline Barr and Taslitz ${ }^{22}$ & Physical therapist & Conventional & Back & $20 \mathrm{~min}$ \\
\hline Day et al. ${ }^{18}$ & Physical therapist & $\begin{array}{l}\text { Effleurage } \\
\text { Pétrissage }\end{array}$ & Back & $30 \mathrm{~min}$ \\
\hline
\end{tabular}




\section{Effects on circulation}

Because of the perceived effect of massage on the circulation $^{3}$, a proportion of the studies into massage have investigated this aspect ${ }^{11-19}$.

Early studies ${ }^{11}$ used venous occlusion plethysmographs to determine the effects of two massage techniques on the blood flow in normal and diseased extremities. One technique (Table 1) resulted in consistent and significant increases in average blood flow.

The second technique was described as deep stroking and kneading massage which only gave rise to a moderate change in total blood flow in patients with flaccid paralysis. It was noted that vigorous stimulating, forceful massage was not a routine procedure and that it may actually damage flaccid muscle and other soft tissues if performed incorrectly, although no evidence was presented to support this note of caution. This paper also noted that it was impossible to determine whether the cause of an increase in temperature (hence blood flow) was due to mechanical action or reflex stimulation. The reflex effect was also investigated by Ebel and Wisham ${ }^{12}$ who noted a considerable increase in skin temperature in all subjects on the massaged calf and also slightly on the opposite limb. This contralateral effect, it was speculated, was reflex in nature.

Animal experiments have been performed to study the effect of various procedures on the flow of lymph ${ }^{13}$. By observing the flow of lymph from the thoracic ducts of dogs, this study concluded that passive and active exercises to the hind legs and thighs of dogs were just as effective as massage in increasing lymph flow. However, the kneading and stroking massage was only introduced when the dogs developed leg oedema due to hypoproteinaemia, making the results difficult to extrapolate to normal subjects or athletes.

A study on the denervated gastrocnemius muscles of cats suggested that massage was effective in maintaining weight and strength but only in combination with electrical stimulation ${ }^{14}$. Other methods used to evaluate effects on the circulation have included xenon-133 as a tracer ${ }^{15,16}$. These studies are among the few to use comparable methods of investigation. Both studies revealed an increase in clearance rate with tapôtement and effleurage, but these changes were small and transient. It was assumed that tapôtement ${ }^{15}$ was vigorous and traumatic enough to have caused muscular contractions sufficient to affect blood flow and that the reason effleurage ${ }^{16}$ had an effect on xenon-133 clearance was due to the centripetal force emptying the capillaries and venous beds. However, this was such a small effect that even light muscular exercise would cause a greater increase in blood flow.

Other studies ${ }^{17-19}$ have attempted to evaluate the effects of massage on blood parameters. Massage, which was described as 'fairly vigorous conventional whole-body', was applied to nine healthy volunteers $^{17} ; 22$ blood parameters were measured. The only significant rises were in creatine kinase $(\mathrm{CK})$ and lactate dehydrogenase (LDH). This was explained by the mechanical trauma to the muscles and subse- quent increase of cell membrane activity caused by the vigorous massage technique. This is an important objective measurement of the damage that can be caused to muscle through injudicious use of massage.

Massage has also been shown to have no significant effect on serum levels of $\beta$-endorphin and $\beta$-lipotrophin levels ${ }^{18}$. Unfortunately, this was performed on a small number of pain-free subjects which the authors concede may have influenced their results.

However, the lack of any other blood changes contrasted with other work $^{19}$, the results of which indicated that whole-body massage induced an acute decrease in blood and plasma viscosity and haematocrit in both ankylosing spondylitis patients and healthy subjects. These findings were explained by massage causing a decrease in sympathetic tone or, alternatively, by a reactive hyperaemia causing haemodilution. It was also postulated that mechanical, muscular manipulation may reintroduce stagnant flow from the microvasculature into the active circulation. Interstitial fluid could also be mechanically compressed into the circulation by the same method. Although the benefits of these findings are the amelioration of muscle perfusion in ankylosing spondylitis patients, the benefits to athletes have not been studied. There have also been studies to verify the effects of massage on skeletal muscle tone $e^{20,21}$, and on autonomic functions ${ }^{22}$.

The clinical implications for athletes could be reduction of muscle spasm or cramps due to injury or fatigue.

Objective measurement of muscle tone was obtained using the Hoffman reflex ( $\mathrm{H}$ reflex). This measurement of muscle tone is used extensively to determine the excitability of the spinal reflex pathway and has been used previously to investigate the efficacy of other therapies, such as ice, tendon pressure and passive muscle stretching. This study could compare these techniques with massage using the same objective measurement.

In one study ${ }^{20}$ the calf muscle of nine healthy individuals was massaged one-handed using a pétrissage technique for $3 \mathrm{~min}$. Results showed that there was only a significant decrease in $\mathrm{H}$ reflex amplitudes during the application of treatment $(P<$ 0.01 ; one-way repeated measures analysis of variance with Neumann Keuls post hoc procedures). These amplitudes returned to normal immediately on termination of the massage. This seemed to indicate that massage not only reduces the level of motoneuron excitability and consequently of muscle reflex activity, but is quite specific with much less effect on the contralateral limb than previously thought and with inhibition taking place only during treatment. This was confirmed in a later study using the same techniques of massage and $\mathrm{H}$ reflex measurement ${ }^{21}$. The question is, how can massage with its multidimensional sensory input cause a decrease in the level of motoneuron excitability? It is suggested ${ }^{21}$ that the pétrissage used may have the same effect as intermittent pressure techniques such as muscle tapping, which also reduces the $\mathrm{H}$ reflex.

Studies on the autonomic functions of the body indicated a small trend towards an increase of 
sympathetic activity following massage to the back ${ }^{22}$. Unfortunately, this paper is unable to establish whether the changes were due to physical or mental processes. This would be an important consideration for a physiotherapist treating an athlete before competition as the parameters measured were heart rate, body temperature, respiratory rate and sweating which athletes would be trying to control in the stressful pre-event environment. There were also subjective observations such as thirst and sleep.

To summarize - studies on the physiological effects have been contradictory and difficult to compare and evaluate due to different massage techniques utilized (Table 1) and different methods of analysis. As yet there has not been any definite and consistent evidence that massage enhances body physiology apart from its effect on skeletal muscle tone. An important finding has been an increase in $\mathrm{LDH}$ and $\mathrm{CK}$ after vigorous massage indicating muscle trauma.

\section{Post-event massage}

Post-event massage is often applied to the athlete in the belief that this will overcome fatigue and help recovery ${ }^{23}$.

One study ${ }^{24}$ evaluated the effects of two types of massage (manual and mechanical) on recovery from overall muscular and physiological fatigue (Table 1). It was concluded that there were definite recuperative benefits physiologically and locally from the two types of massage, but not from rest. Results were not analysed statistically and the subject numbers were small. The study also failed to explain the processes by which fatigue could be countered by massage and if the manual massage technique was similar to the vigorous vibratory massage of the 'thumper' machine. However, the use of a mechanical massager for athletes without availability or finance for a masseur was advocated.

A more recent study ${ }^{25}$ also investigated the effects of vibratory mechanical massage on short-term recovery from muscular fatigue. Using 12 moderately healthy men, the results of this experiment indicated that there was no statistically significant difference in the rate of fatigue in either static exercises or after dynamic exercise (cycling) between vibratory mechanical massage or rest in the quadriceps muscles (repeated measures analysis of variance and post hoc analysis with correlated $t$ tests). The reason why massage had no effect on the rate of fatigue was discussed. If one of the reasons for fatigue is restriction of blood to the active muscle due to muscle contractions, then delivery and washout must occur between contractions.

If during strenuous muscle contractions the motor unit firing declines, this may be due to a decrease in blood flow. It seemed reasonable to suggest that an increase in blood flow in excess of metabolic requirements would enhance the return of all processes to homeostatic levels.

Increased blood flow was thought to be a major effect of vibratory massage, yet this type of massage did not help recovery in this study. The reason for this was that the mechanical massage set up a tonic vibration reflex when it was used on muscles. Therefore, when the mechanical massage was being applied for $4 \mathrm{~min}$, the muscle was actively contracting. The study speculated that any beneficial effects of blood flow (which were small) would be expended in recovering from the effects of the tonic vibration reflex set up by the massage. It was concluded that short-term recovery from intense muscular activity was not augmented by vibratory mechanical massage.

\section{Pre-event massage}

Massage is often used by athletes before an event, yet there has also been little scientific evidence to support the hypothesis that pre-event massage will enhance an athlete's performance.

A physiological evaluation of massage in this context ${ }^{26}$ was undertaken on 10 healthy men. Each subject was in either a control group (no massage) or the treatment group (with massage) before $10 \mathrm{~min}$ submaximal exercise (Table 1). Parameters measured were $\dot{V}_{2}$, cardiac output, heart rate, stroke volume, $\mathrm{a}-\overline{\mathrm{v}} \mathrm{O}_{2}$ diff and blood pressure. It was found that the pre-event massage did not provide the subjects with an increased oxygen flow to the tissues, therefore both exercise tests at $80 \%$ of maximum heart rate required the same oxygen consumption. There were no significant differences in any other parameters $(P$ $>0.05$; paired $t$ test). Without massage, the subjects exercised just as efficiently as when they received the treatment. It was concluded that it was justifiable to state that the physiological effects of sports massage were questionable. Additionally, this study tested for lactic acid levels which is a commonly quoted parameter that massage is said to affect. There were no significant differences in the levels of lactic acid build-up after $10 \mathrm{~min}$ steady-state exercise, with or without massage.

A previous study ${ }^{27}$ investigated the effect of pre-event massage (Table 1) on joint range of movement and quadriceps and hamstring strength.

The experiments were in the following order:

1. General warm-up

2. Warm-up and massage

3. Massage only

4. Warm-up and stretching

The results showed that warm-up and stretching (4) gave significant increases in all ranges of movement (Student's $t$ test). The only other significant finding was that massage and warm-up, both separately and in combination, increased the range of movement at the calf, which seemed to be readily influenced by the action of the ergometer and also by the passive elongation by massage of the muscle and tendon. Muscle strength recorded showed a decrease in isokinetic strength of the hamstrings and in isometric strength of the quadriceps.

Other treatment groups had no effect on strength.

It was concluded that general warm-up and stretching were a better way to increase flexibility. It also had the advantage of being performed by the athlete him/herself without any expensive equipment. This paper highlights the common request 
from athletes for massage in the belief that this will substitute for any warm-up or stretching and help prevent injury. The results are of clinical importance and this is one of few papers published which compares three common strategies used before competition.

More recently, an investigation of the effects of pre-performance massage on the stride frequency of sprinters was undertaken ${ }^{7}$. This used a counterbalance design to identify the presence of order or learning effect. Results showed no statistically significant difference between the group trials or any interaction $(P>0.05$; Student's $t$ test). However, the magnitude and direction of the means between the conditions did show a trend towards a positive effect on stride frequency of pre-performance massage. It was emphasized that the results were due to $30 \mathrm{~min}$ of extensive and conscientious treatment by an experienced masseur and that cursory massage may be of less value. The author also speculated that the conventional level of significance $(P<0.05)$ may be too stringent when studying sprinters. He bases this on the assumption that massage is not detrimental (which it may be ${ }^{17}$ ) and that it is low in cost. Although true in terms of materials this is not true in terms of the number of hours taken to apply massage.

To summarize - although massage is widely used in the belief that it helps muscle recover from fatigue and can enhance performance, the studies to confirm this are few in number and contradictory. It should be noted that these studies are almost all performed in a laboratory setting. Although this enables accurate analysis and data collection, it may not reflect the effects of stress of competition and other psychological factors.

\section{Sports-specific massage}

Massage can be regarded as sports specific. Different sports and even different disciplines within a sport may require a different type or amount of massage. This may create problems if results of the effects of massage in one sport are extrapolated to another sport.

Cycling has traditionally regarded a masseur as an integral part of its team. Recent studies have investigated the scientific evidence of the effects of massage on élite cyclists ${ }^{28,29}$. In the first study ${ }^{28}$, six élite cyclists performed a 4 -day stage race $(161 \mathrm{~km}$ day $^{-1}$ ) by computerized race simulation. After each stage the cyclists were given either massage for $20 \mathrm{~min}$, or $30 \mathrm{~min}$ blind placebo microwave.

The race simulation was repeated 18 days later but the post-race treatments were altered. Parameters measured were serum muscle and liver enzymes to detect muscle damage and recovery status. There were no significant differences between massage and placebo in pre-race, post-race, post-treatment, or 3 days post-race parameters $(P<0.05)$. There were also found to be no differences in performances measured by $40-\mathrm{km}$ split times or final $161-\mathrm{km}$ times.

It was concluded that post-event massage did not expedite muscle recovery or improve performance times from ultra-endurance cycling. Although under laboratory conditions, this study was one of the few to place athletes under physical stress similar to that in competition. It is after the types of conditions replicated in this study that a masseur is normally used rather than a 1-day stage race.

Owing to the emphasis placed on the emotional and psychological effect that massage can have on an athlete's mood and performance, the same researchers undertook a second study ${ }^{29}$. Six élite cyclists in the same experimental conditions were assessed as to the effects of post-race massage on Ratings of Perceived Exertion, Feeling Scale and Profile of Mood State. Results revealed no significant difference between the massage and the placebo conditions on any of the psychological profiles (repeated measures analysis of variance with Neumann Keuls post hoc analysis). It was concluded that post-race massage did not provide ergogenic enhancement of psychological status or performance capacity when compared with placebo. This contrasted with results from an earlier study by Weinberg $e t ~ a l .{ }^{30}$, which concluded that there was a greater relationship between massage and positive mood enhancement than between exercise (running) and positive mood enhancement.

\section{Implications}

Watt (personal communication, 1992) stated that 50 non-specific massages were performed on the UK team within 2 days at the European Indoor Athletic Championships in 1986 (i.e. general leg or body massage not for a specific problem). The number of massages carried out by physiotherapists and masseurs for the UK Team at the Winter Olympics at Albertville in 1992 was at least 164. The number carried out for the UK Team at the Summer Olympics at Barcelona in 1992 was at least 787 (Brown, personal communication, 1992). There are many requests from athletes competing at the élite level for this technique and yet at present there is little or no evidence that it is beneficial.

Rather than massaging a limb it may be necessary for a physiotherapist to supervise and perform passive stretching and give advice on warming up in preparing an athlete for competition. A further implication is based on the assumption by a number of authors that massage is not detrimental. Arkko et al. ${ }^{17}$ demonstrated mechanical trauma to muscle by a vigorous massage technique. On this evidence the care of an élite athlete should not be left to inexperienced or unqualified practitioners.

Massage continues to be a contentious issue in the sporting context. Recent studies on healthy individuals and élite athletes suggest that caution should be used when extrapolating results from the subjects of earlier studies in the hospital setting.

Lack of comparable instrumentation and different research designs have led to little agreement among researchers over the type of massage to be employed or the length of time needed to be effective. Indeed, the length of time and degree of use are often based solely on the athlete's preference and not on scientific data. 
It is clear that the role of massage in the athlete needs to be evaluated further in an attempt to resolve some of these points and in an attempt to justify the requests from athletes for a time-consuming technique.

\section{Acknowledgements}

The author wishes to thank an anonymous reviewer for helpful comments and $\mathrm{Mr}$ Peter Keen for his help and advice.

\section{References}

1 Kamenetz HL. History of massage. In: Basmajian JV, ed. Manipulation, Traction and Massage. Baltimore, USA: Williams and Wilkins, 1985: 211-49.

2 Scull CW. Massage - physiologic basis. Arch Phys Med 1945; 26: $159-67$.

3 Stamford B. Massage for athletes. Physician and Sports Medicine 1985; 13: 178

4 Kuprian W. Physical Therapy for Sports. Philadelphia, USA: WB Saunders, 1981: 7-51.

5 Hofkosh JM. Classical massage. In: Basmajian JV, ed. Manipulation, Traction and Massage. Baltimore, USA: Williams and Wilkins, 1985: 263-9.

6 Holey E. Connective tissue techniques (Letter to the Editor). Physiotherapy 1991; 77: 460.

7 Harmer PA. The effect of pre-performance massage on stride frequency in sprinters. Athletic Training 1991; 26: 55-9.

8 Palastanga N. Connective tissue massage. In: Grieve GP, ed. Modern Manual Therapy of the Vertebral Column. Edinburgh, UK: Churchill Livingstone, 1986: 827-33.

9 Goats GC, Weir KAI. Connective tissue massage. Br J Sports Med 1991; 25: 131-3.

10 Cyriax J. Textbook of Orthopaedic Medicine: Treatment by Manipulation, Massage and Traction, Volume 2. London, UK: Baillière Tindall, 1980 .

11 Wakim KG, Martin GM, Terrier JC, Elkins EC, Krusen FH The effects of massage on the circulation in normal and paralysed extremities. Arch Phys Med 1949; 30: 135-44.

12 Ebel A, Wisham LH. Effect of massage on muscle temperature and radiosodium clearance. Arch Phys Med 1952; 33: 399-405.

13 Elkins EC, Herrick JF, Grindlay JH, Mann FC, Deforest RE. Effect of various procedures on the flow of lymph. Arch Phys Med 1953; 34: 31-9.
14 Suskind MI, Hajek NM, Hines HM. Effects of massage on denervated skeletal muscle. Arch Phys Med 1946; 27: 133-5.

15 Hovind H, Nielsen SL. Effect of massage on blood flow in skeletal muscle. Scand I Rehabil Med 1974; 6: 74-7.

16 Hansen TI, Kristensen JH. Effect of massage, shortwave diathermy and ultrasound upon ${ }^{133} \mathrm{Xe}$ disappearance rate from muscle and subcutaneous tissue in the human calf. Scand J Rehabil Med 1973; 5: 179-82.

17 Arkko PJ, Pakarinen AJ, Kari-Koskinen O. Effects of whole body massage on serum protein and hormone concentrations, enzyme activities and haematological parameters. Int Sports Med 1983; 4: 265-7.

18 Day JA, Mason RR, Chesrown SE. Effect of massage on serum level of $\beta$-endorphin and $\beta$-lipotrophin in healthy adults. Phys Ther 1987; 67: 926-30.

19 Ernst E, Matrai A, Magyarosy I, Liebermeister RGA, Eck M, Breu MC. Massages cause changes in blood fluidity. Physiotherapy 1987; 73: 43-5.

20 Morelli M, Seaborne DE, Sullivan J. Changes in H-reflex amplitude during massage of triceps surae in healthy subjects. J Orthop Sports Phys Ther 1990; 12: 55-9.

21 Sullivan SJ, Williams LRT, Seaborne DE, Morelli M. Effects of massage on alpha motoneuron excitability. Phys Ther 1991; 71: $555-60$.

22 Barr JS, Taslitz N. The influence of back massage on autonomic functions. Phys Ther 1970; 50: 1679-91.

23 Wakim KG. Physiologic effects of massage. In: Basmajian JV ed. Manipulation, Traction and Massage. Baltimore: Williams and Wilkins, 1985, 256-61.

24 Balke B, Anthony J, Wyatt F. The effects of massage treatment on exercise fatigue. Clin Sports Med 1989; 1: 189-96.

25 Carafelli E, Sim J, Carolan B, Libesman J. Vibratory massage and short term recovery from muscular fatigue. Int Sports Med 1990; 11: 474-8.

26 Boone T, Cooper R, Thompson WR. A physiologic evaluation of the sports massage. Athletic Training 1991; 26: 51-4.

27 Wiktorsson-Moller M, Oberg B, Eksrand J, Gillquist J. Effects of warming up, massage and stretching on range of motion and muscle strength in the lower extremity. Am J Sports Med 1983; 11: 249-52.

28 Drews T, Krieder B, Drinkard B et al. Effects of post even massage therapy on repeated endurance cycling. Int J Sports Med 1990; 11: 407.

29 Drews T, Krieder RB, Drinkard B, Jackson CW. Effects of post event massage therapy on psychological profiles of exertion, feeling and mood during a four day ultraendurance cycling event. Med Sci Sport Exerc 1991; 23: 91.

30 Weinberg RE, Jackson A, Kolodny K. The relationship of massage and exercise to mood enhancement. Sports Psychologist 1988; 2: 202-11. 